\title{
Filmes multicamadas para materiais fertiliberadores baseados em carboximetilcelulose/quitosana/zeólitas-fertilizantes
}

A comunidade científica tem intensificado os estudos sobre novos materiais a fim de utilizar suas propriedades na fabricação de fertilizantes de eficiência melhorada. Estes materiais são atrativos, pois liberam os nutrientes essenciais às plantas de forma prolongada. Além disso, diminuem os danos ambientais, aumentam a praticidade durante a aplicação, reduzem o consumo de fertilizantes e aumentam a produtividade. Dessa forma, este trabalho visou obter e caracterizar fertilizantes de eficiência melhorada baseados em zeólita (Ze) natural adsorvida com macro e micronutrientes, carboximetilcelulose (CMC) e quitosana (Ch). Inicialmente, buscou-se avaliar a capacidade de adsorção da $\mathrm{Ze}$ em relação aos nutrientes potássio $\left(\mathrm{KNO}_{3}\right)$, cobre $\left(\mathrm{CuSO}_{4} \cdot 5 \mathrm{H}_{2} \mathrm{O}\right)$, manganês $\left(\mathrm{MnSO}_{4} \cdot \mathrm{H}_{2} \mathrm{O}\right)$, zinco $\left(\mathrm{ZnSO}_{4} \cdot 7 \mathrm{H}_{2} \mathrm{O}\right)$ e ferro $\left(\mathrm{FeSO}_{4} \cdot \mathrm{H}_{2} \mathrm{O}\right)$. Estudos de cinética e isotermas de adsorção foram realizados. Após o processo de adsorção, a Ze enriquecida pelos nutrientes foi incorporada à solução de CMC para a obtenção de filmes mono e multielementares por evaporação de solvente (casting). Adicionalmente, foram preparados filmes multicamadas contendo $\mathrm{Ch}$ ou CMC-Zemicronutrientes. Verificou-se que Ze apresenta maior seletividade pelos íons $\mathrm{Cu}^{2+} \mathrm{e} \mathrm{Zn}^{2+}$ em detrimento aos íons $\mathrm{Fe}^{2+}$ e $\mathrm{Mn}^{2+}$ estando de acordo com as propriedades físicoquímicas dos íons. Filmes multicamada multielementares contendo apenas CMC diminuíram significativamente a liberação em água para todos os nutrientes utilizados. Na segunda etapa realizou-se ensaios de liberação em solo. Os filmes multicamadas mono e multielementar foram produzidos por prensagem. As análises em solo tiveram duração de 80 dias. Concomitantemente, o fertilizante comercial Basacote ${ }^{\circledR}$ também foi avaliado com objetivo de comparar os dados de liberação entre os materiais propostos. Os resultados demonstraram que os materiais desenvolvidos apresentam resultados similares ao produto comercial em relação a liberação de macro e micronutrientes. Os filmes obtidos nesse trabalho têm potencial de aplicação comercial, devido ao baixo custo e simplicidade de produção, atribuindo aos materiais valor agregado e ambiental, pois os mesmos contribuem para práticas agrícolas mais sustentáveis.

Palavras-Chaves: Agricultura Sustentável; Fertilizante de Eficiência Melhorada; Macro e Micronutrientes; TDR; Zeólita; Quitosana; Carboximetilcelulose. 